Article

\title{
Impact of Methanol Concentration on Properties of Ultra-Nanocrystalline Diamond Films Grown by Hot-Filament Chemical Vapour Deposition
}

\author{
Lidia Mosińska ${ }^{1, *(\mathbb{C})}$, Robert Szczęsny ${ }^{2} \mathbb{D}$, Marek Trzcinski ${ }^{3}$ and Mieczysław Karol Naparty ${ }^{3}$ \\ 1 Institute of Physics, Kazimierz Wielki University, Powstańców Wielkopolskich 2, 85-090 Bydgoszcz, Poland \\ 2 Faculty of Chemistry, Nicolaus Copernicus University in Torun, Gagarina 7, 87-100 Torun, Poland; \\ Robert.Szczesny@umk.pl \\ 3 Institute of Mathematics and Physics, Bydgoszcz University of Science and Technology, Al. S. Kaliskiego 7, \\ 85-796 Bydgoszcz, Poland; marekt@pbs.edu.pl (M.T.); naparty@pbs.edu.pl (M.K.N.) \\ * Correspondence: lidiamosinska@ukw.edu.pl
}

check for

updates

Citation: Mosińska, L.; Szczęsny, R.; Trzcinski, M.; Naparty, M.K. Impact of Methanol Concentration on Properties of Ultra-Nanocrystalline Diamond Films Grown by

Hot-Filament Chemical Vapour Deposition. Materials 2022, 15, 5. https://doi.org/10.3390/ma15010005

Academic Editor: Alexander N. Obraztsov

Received: 10 November 2021 Accepted: 18 December 2021 Published: 21 December 2021

Publisher's Note: MDPI stays neutral with regard to jurisdictional claims in published maps and institutional affiliations.

Copyright: (C) 2021 by the authors. Licensee MDPI, Basel, Switzerland. This article is an open access article distributed under the terms and conditions of the Creative Commons Attribution (CC BY) license (https:// creativecommons.org/licenses/by/ $4.0 /)$.

\begin{abstract}
Diamond is a very interesting material with a wide range of properties, making it highly applicable, for example, in power electronics, chemo- and biosensors, tools' coatings, and heaters. Due to the high demand for this innovative material based on the properties it is already expected to have, it is important to obtain homogeneous diamond layers for specific applications. Doping is often chosen to modify the properties of layers. However, there is an alternative way to achieve this goal and it is shown in this publication. The presented research results reveal that the change in methanol content during the Hot Filament Chemical Vapour Deposition (HF CVD) process is a sufficient factor to tune the properties of deposited layers. This was confirmed by analysing the properties of the obtained layers, which were determined using Raman spectroscopy, scanning electron microscopy (SEM), X-ray diffraction (XRD), and an atomic force microscope (AFM), and the results were correlated with those of X-ray photoelectron spectroscopy (XPS). The results showed that the increasing of the concentration of methanol resulted in a slight decrease in the $\mathrm{sp}^{3}$ phase content. At the same time, the concentration of the $-\mathrm{H},-\mathrm{OH}$, and $=\mathrm{O}$ groups increased with the increasing of the methanol concentration. This affirmed that by changing the content of methanol, it is possible to obtain layers with different properties.
\end{abstract}

Keywords: ultra-nanocrystalline diamond; hot filament chemical vapour deposition; nanoparticles; trans-polyacetylene

\section{Introduction}

Today, the search for new materials with specific properties is still ongoing. The materials can be divided into two main groups: organic and inorganic. Each of these groups is characterised by specific properties and can be used to build specific devices [1,2]. In recent years, interest in the preparation and investigation of properties of thin film structures has significantly grown. This has allowed the creation of new devices such as sensors, detectors, optoelectronic elements, and electrochemical electrodes [3-8]. The possibility of surface functionalisation has enabled the creation of selective sensors operating in specific conditions $[9,10]$.

Currently, there are many materials, which are used as electrode materials for chemical sensors. Diamond films are, among other materials, studied for this purpose. The challenge for thin diamond layers is to ensure both high sensitivity and selectivity as well as high electrochemical stability and resistance to aggressive environments [11]. CVD diamond layers also find new applications as protective coatings in micro electrochemical devices, supercapacitors, and fuel cells [12]. Ultra-nanocrystalline diamond (UNCD) layers are considered as a prospective electrode material due to its wide band gap, high breakdown voltage, and small dielectric constant [13-16]. It is necessary to tune the mechanical, 
electrical, and chemical properties to specific applications. The most common strategy for modifying CVD diamond layers is doping with boron and nitrogen $[17,18]$, which results in a Fermi level shift and changes in the band gap. A wide range of physical or mechanical properties of CVD diamonds depends on the ratio of the $s p^{2}$ and $s p^{3}$ phase [19-22].

Recently, several efforts have been made to reduce diamond grain sizes, as smaller grain sizes give better electrochemical properties [23]. This paper describes the synthesis of UNCD films using the hot filament chemical vapour deposition (HF CVD) technique. Methanol is used as a carbon precursor. We show that the UNCD grains grown during the HF CVD process can be easily controlled by changing the methanol concentration in the reaction gas mixture $\left(\mathrm{H}_{2} / \mathrm{CH}_{4} \mathrm{OH}\right)$, which, in this study, ranged between 4 and $7 \mathrm{vol} \%$.

\section{Materials and Methods}

\subsection{HF-CVD Growth}

The diamond films were synthesized in a home-made HF CVD reactor. As a filament wire with a cross section of $0.5 \mathrm{~mm}$ in a form of spring, with a coil diameter of $5 \mathrm{~mm}$, tungsten was used. Quartz plate (100) was used as a substrate, with dimensions of $5 \times 5 \mathrm{~mm}^{2}$. Before being placed in the reaction chamber, quartz substrate was subjected to an ultrasonic bath in chloroform for $4 \mathrm{~min}$, in a suspension of diamond powder in methanol for $6 \mathrm{~min}$, and finally in methanol for $6 \mathrm{~min}$. The time deposition of each sample was $6 \mathrm{~h}$. The mixture of methanol vapour and hydrogen $\left(\mathrm{CH}_{3} \mathrm{OH} / \mathrm{H}_{2}\right)$ was used as a working gas. CVD synthesis was carried out at total pressure of 50 mbar, a substrate temperature of $\sim 1000 \mathrm{~K}$, and a working gas flow rate of $100 \mathrm{sccm}$. The methanol concentration in working gas was changed between 4 and $7 \mathrm{vol} \%$. Thus, the fine-tuning of the properties of this type of layer by using only one process parameter allowed the fabrication of films with various properties.

\subsection{Material Characterisation}

The surface morphology was investigated by scanning electron microscopy (SEM) using a Quanta 3D FEG (VP mode, SE detector) (FEI, Hillsboro, OR, USA). The particle size was measured using the SEMAFORE program.

Structural information came from X-ray diffraction (XRD) measurements; all materials were also characterised by powder X-ray diffraction (PXD) using Philips XPERT Pro $\theta-2 \theta$ and D8 Bruker diffractometers with $\mathrm{CuK} \alpha$ radiation ((PANalytical-Malvern Panalytical Ltd., Malvern, UK).

The surface topography of the UNCD films was examined using the Bruker Innova atomic force microscope (AFM) from Bruker with standard silicon tips for use in tapping mode. The scan size was $5 \mu \mathrm{m} \times 5 \mu \mathrm{m}$. The mean surface roughness was determined using the NanoScope Analysis software (version 1.40).

The Model 2450 SourceMeter SMU Instrument was used for resistance measurements in 2-point probe configuration. The spacing between electric contacts (tungsten needles) was set to $1 \mathrm{~mm}$.

The Raman spectroscopy measurements were carried out on a Senterra (Bruker Optik $\mathrm{GmbH}$, Ettlingen, Germany) spectrometer using a $532 \mathrm{~nm}$ excitation laser. The analysis of the Raman scattering spectra was performed after removing the fluorescent background by means of asymmetric least square smoothing. Characteristic bands were fitted with the Gaussian-Lorentzian cross product function.

X-ray photoelectron spectroscopy (XPS) measurements were performed under ultrahigh vacuum (UHV) conditions (base pressure $\leq 2 \times 10^{-10} \mathrm{mbar}$ ). The spectra were recorded with a VG-Scienta R3000 (Uppsala, Sweden) hemispherical analyser using AlK $\alpha$ $(1486.6 \mathrm{eV})$ as a radiation source. The energy step was set to $\Delta \mathrm{E}=100 \mathrm{meV}$. The pass energy of the analyser was set to $50 \mathrm{eV}$ and the spectra were calibrated using the W4f level of $31.6 \mathrm{eV}$. 


\section{Results}

3.1. Scanning Electron Microscopy, X-ray Diffraction, and Atomic Force Microscopy

Figure 1 shows SEM images of the UNCD films grown at different methanol concentrations. The fabricated diamond layers are smooth and the homogenous nanocrystals are clearly visible. The influence of methanol concentration on crystalline size is apparent. The size of UNCD grains, estimated from high-resolution SEM, can be seen to decrease with the increasing of the methanol concentration from $24 \pm 2 \mathrm{~nm}$ and $13 \pm 2 \mathrm{~nm}$ (Figure 1a-d).

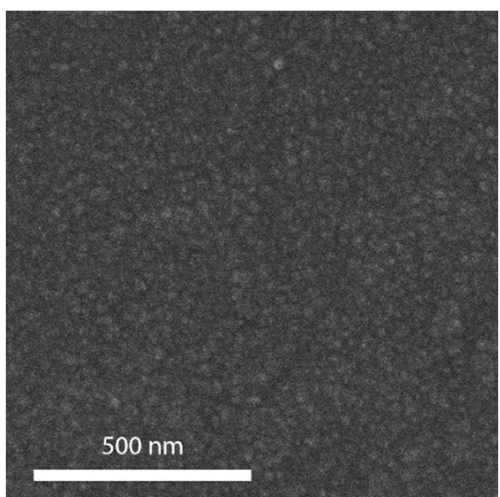

(a)

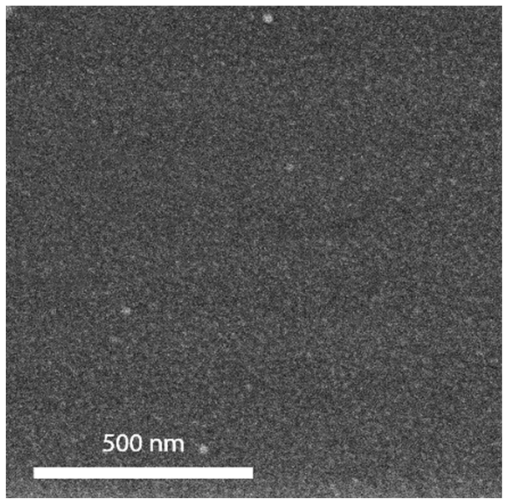

(c)

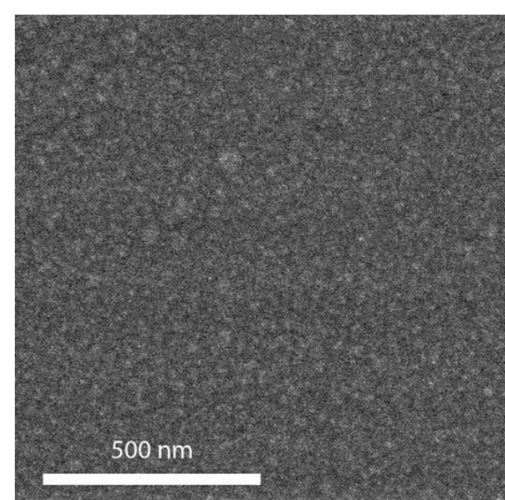

(b)

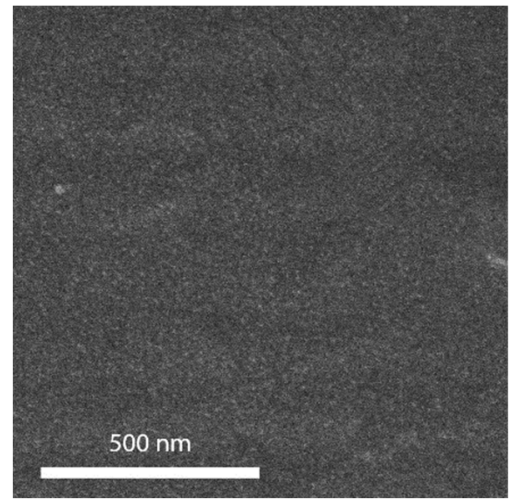

(d)

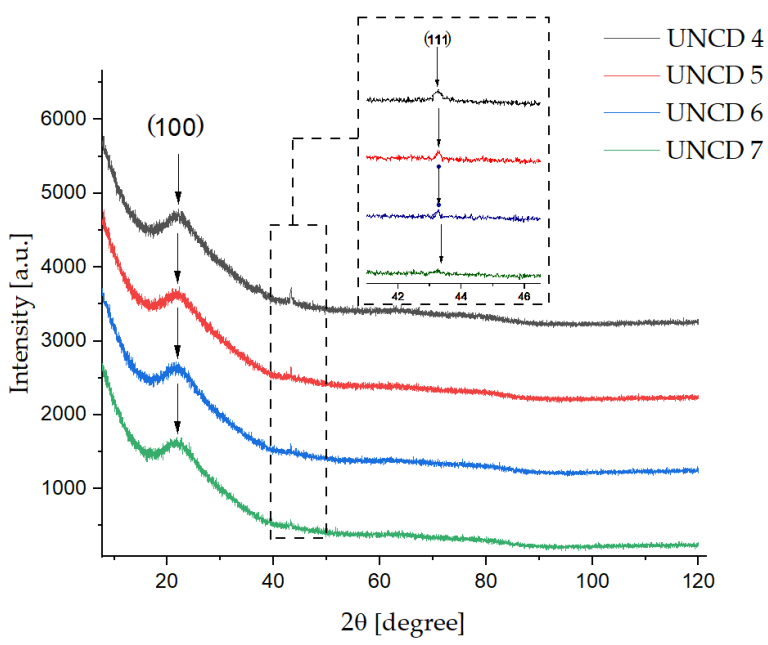

(e)

Figure 1. CVD diamond films, with the content of the vapours of methanol in quantities of (a) $4 \%$ (UNCD-4), (b) 5\% (UNCD-5), (c) 6\% (UNCD-6), and (d) 7\% (UNCD-7), with (e) XRD peaks of diamond films. 
The sizes of the crystals were determined using XRD, based on Scherrer's equation. All spectra for the (111) diamond reflexes, with planes at $2 \theta=43.5^{\circ}$, were applied and the grain sizes were about 8-3 $\pm 2 \mathrm{~nm}$, which confirmed the presence of ultranano-sized crystallites [24]. The observed peak from (100), with planes at $2 \theta=21.7^{\circ}$, was dedicated to the quartz substrate.

The topographies of deposited layers were also analysed by atomic force microscopy. The mean surface roughness decreased with the increasing of the methanol content. The values of Ra and Rq, for the tested samples (UNCD-4, UNCD-5, UNCD-6, and UNCD-7), were $6.56 \mathrm{~nm}$ and $8.42 \mathrm{~nm}, 2.19 \mathrm{~nm}$ and $2.89 \mathrm{~nm}, 1.17 \mathrm{~nm}$ and $1.73 \mathrm{~nm}$, and $1.43 \mathrm{~nm}$ and $1.89 \mathrm{~nm}$, respectively. Figure 2 shows the AFM images recorded for the UNCD diamond films, confirming the presence of ultranano-sized diamond crystallites.

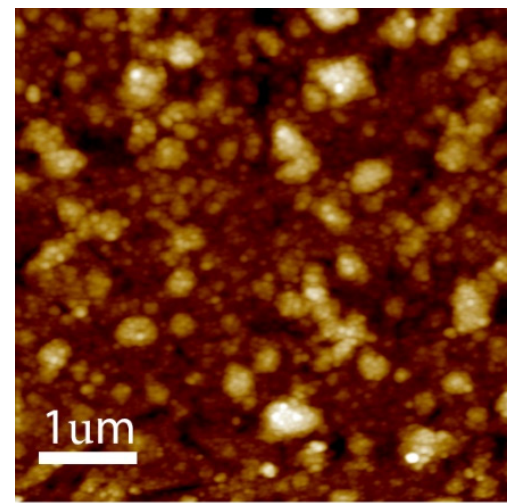

(a)

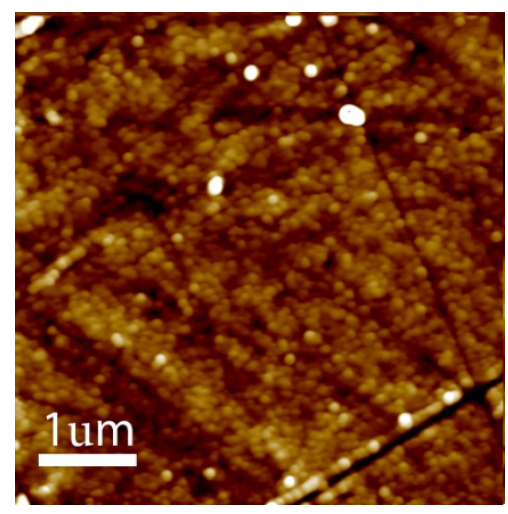

(c)

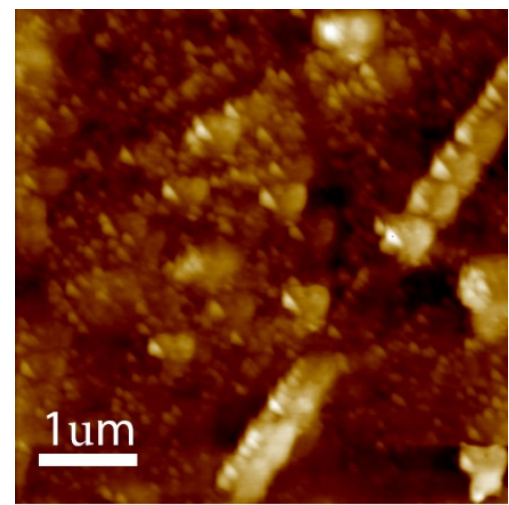

(b)

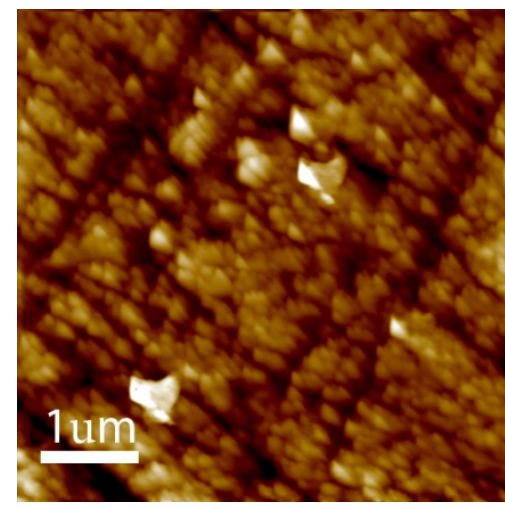

(d)

Figure 2. AFM 2D topography of (a) 4\% (UNCD-4), (b) 5\% (UNCD-5), (c) 6\% (UNCD-6), and (d) 7\% (UNCD-7).

Changes in methanol concentration also influenced the surface resistance. Figure $3 \mathrm{~b}$ compares the resistance measurements performed at the UNCD layers. Slight changes in the concentration of methanol (4-7\%) caused a thirteen-fold increase in the surface resistance of the layer. We attribute this behaviour to the decreasing grain size of the diamond, which probably increased the specific surface of the film. 
(a)

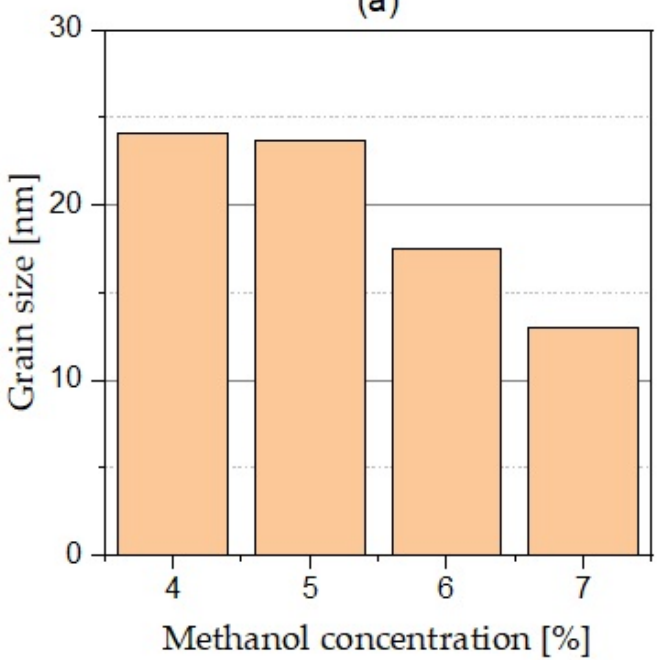

(b)

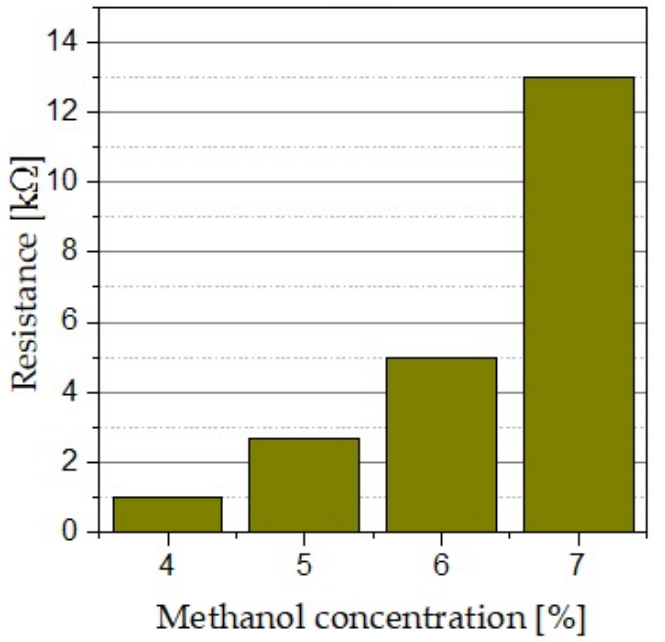

Figure 3. Methanol vapour content for diamond films on the basis of: (a) grain size and (b) layer resistivity.

\subsection{Raman Spectroscopy}

Raman spectroscopy is the most common method used to characterise the different forms of carbon. Figure 4 shows the Raman spectra of UNCDs grown at different concentrations of the methanol vapours. In addition to a weak sharp diamond peak at $1332 \mathrm{~cm}^{-1}$ (denoted as ' $\mathrm{d}$ '), the spectra showed a broad feature at around $1200 \mathrm{~cm}^{-1}$ (denoted as ' $\mathrm{d}_{\mathrm{nc}}$ ') attributed to small diamond clusters [25-27]. The position of the $d_{n c}$ peak coincided with the vibrational density of states (VDOS) of diamond at $146 \mathrm{meV}\left(1175 \mathrm{~cm}^{-1}\right)$ and $156 \mathrm{meV}$ $\left(1260 \mathrm{~cm}^{-1}\right)$ [28-30].

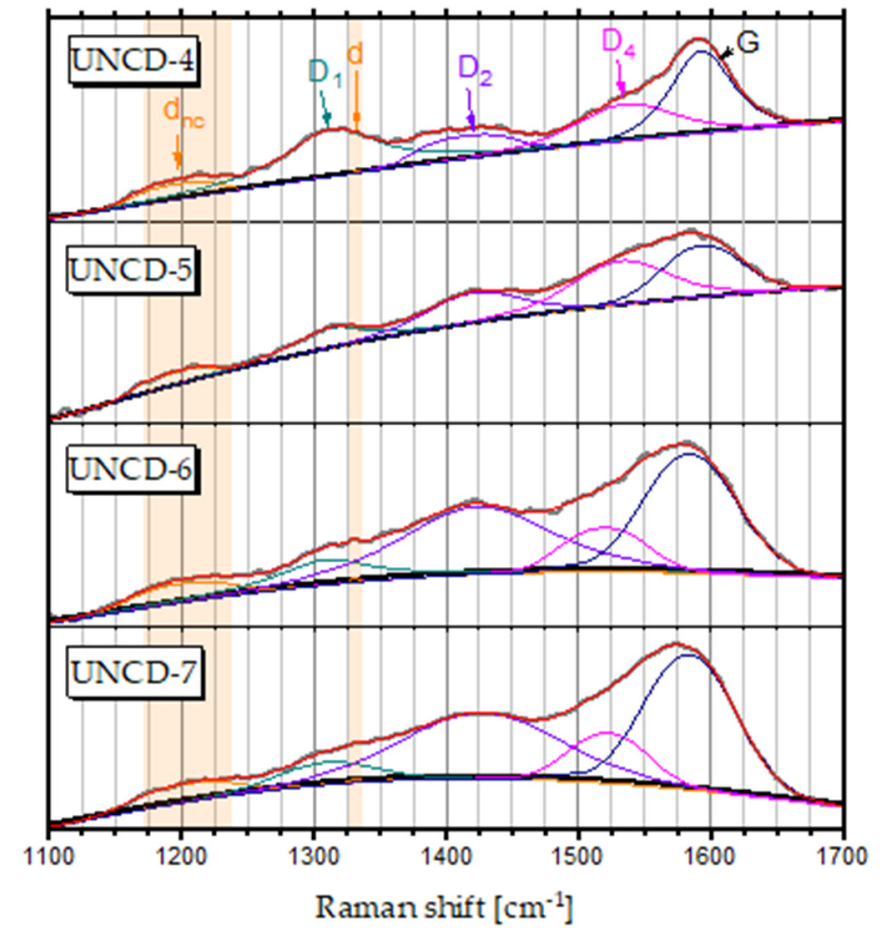

Figure 4. Raman spectra of the UNCD layers grown at methanol concentrations ranging from $4 \%$ to $7 \%$. Various components derived from the peak fitting procedure are also depicted using the following colour code: orange for the diamond components ( $\mathrm{d}$ and $\mathrm{d}_{\mathrm{nc}}$ components), dark cyan for the first C-H $/ s p^{3}$ defect-induced graphene component $D_{1}$, violet and magenta for the $D_{2}$ and $D_{4}$ components, and black for graphene's G-mode. 
The $d_{n c}$ band was Raman inactive in the bulk diamond. However, the selection rules for Raman transitions were broken in UNCD due to the lack of translational symmetry of the crystalline lattice, which gave rise to the observed broad $d_{n c}$ component in the Raman spectra of the tetrahedral carbons [12,31].

The remaining components of the Raman spectra, which are associated with the nondiamond phase, differ essentially from the results already reported for nanocrystalline diamond $[13,31,32]$ These works prove that the $s p^{2}$ fraction in nanocrystalline diamond is a mixture of amorphous carbon and trans-polyacetylene ( $\mathrm{t}-\mathrm{Pa}$ ) macromolecules. The statement was supported by the observed Raman spectra, in which the graphitic D and G bands around 1350 and $1570 \mathrm{~cm}^{-1}$ were accompanied with t-Pa bands around 1150 and $1480 \mathrm{~cm}^{-1}$. However, this interpretation could not be applied to the Raman spectra of the UNCD grown from methanol. Firstly, no single graphitic D component was found at around 1340-1360 $\mathrm{cm}^{-1}$. Secondly, it was impossible to distinguish a band from t-Pa at about $1480 \mathrm{~cm}^{-1}$. Instead of those Raman features, we distinguished broad peaks at around $1310 \mathrm{~cm}^{-1}, 1420 \mathrm{~cm}^{-1}, 1525 \mathrm{~cm}^{-1}$, and $1590 \mathrm{~cm}^{-1}$ that were assigned as $\mathrm{D}_{1}, \mathrm{D}_{2}, \mathrm{D}_{4}$, and G. We used the assignation proposed by Vecera et al. [33], who performed vibrational Raman response calculations of graphene functionalised with hydrogen. According to Vencera's calculations, we assigned the $\mathrm{D}_{1}$ mode to a fingerprint of the oscillations of the carbon atoms directly surrounding the $\mathrm{C}-\mathrm{H} / s p^{3}$ defect, the $\mathrm{D}_{2}$ band that arose due to the oscillations of carbon atoms directly surrounding the $\mathrm{C}-\mathrm{OH} / s p^{3}$ defects, and the next neighbouring atoms that surrounded both the $\mathrm{C}-\mathrm{H} / s p^{3}$ and $\mathrm{C}-\mathrm{OH} / s p^{3}$ defects. The $\mathrm{D}_{4}$ mode was assigned to the oscillations of the next neighbouring atoms surrounding the carbon atoms that were functionalised by the $\mathrm{H}$ and $\mathrm{OH}$ groups. The $\mathrm{G}-$ mode arose from the $\mathrm{E}_{2 \mathrm{~g}}$ vibrational mode of the graphene lattice.

Figure 5 presents the development of individual peak intensities as a function of methanol concentration. We observed a slight decrease in intensity of the nanodiamondrelated $d_{n c}$ component with the increasing of the methanol concentration. At the same time, a significant decrease in the intensity of the $\mathrm{D}_{1}$ line was clearly visible. Thus, we could conclude that the formation of UNCD clusters was coupled with $\mathrm{C}-\mathrm{H} / s p^{3}$ defects. Higher concentrations of methanol in the methanol $/ \mathrm{H}_{2}$ mixture were not conducive to the process of $s p^{3}$ phase formation. On the other hand, higher methanol concentrations resulted in the $\mathrm{C}-\mathrm{OH} / \mathrm{sp}^{3}$ defects that were manifested by the broadening and higher integral intensity of the $\mathrm{D}_{2}$ component.

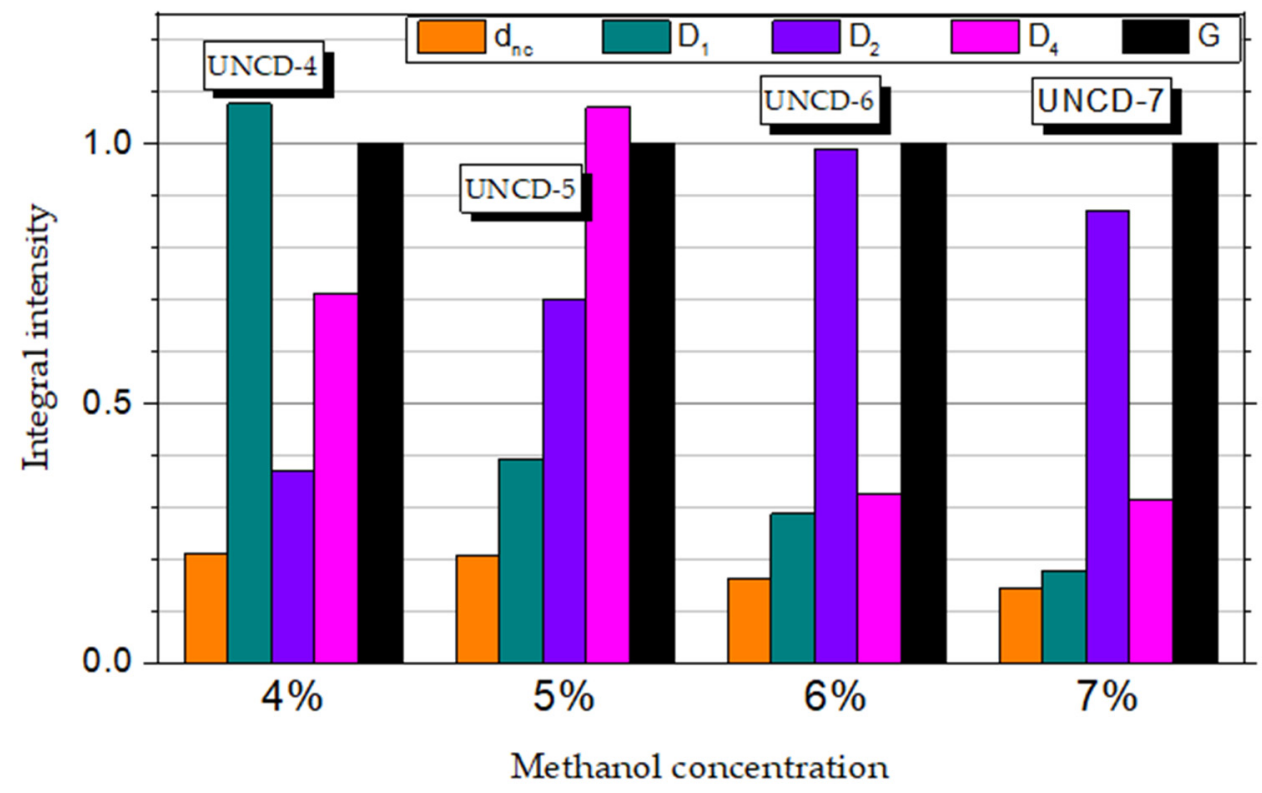

Figure 5. Comparison of integral intensities of Raman features' components normalised to the intensity of the G band. 


\subsection{X-ray Photoelectron Spectroscopy}

Figure 6a- $d$ shows XPS spectra of the $C 1$ s peak of the UNCD samples. The results of $C$ 1 s peak deconvolution with quantification of different carbon bonding states are compared in Figure 6e. By adjusting the energy allocations, then the Gaussian distribution, four types of bonds of the diamond layers could be distinguished: $\mathrm{C}=\mathrm{C} \mathrm{sp}{ }^{2}$ bonding at $284.5 \pm 0.1 \mathrm{eV}$, C-C, C-H sp 3 bonding at $285.4 \pm 0.1 \mathrm{eV}, \mathrm{C}-\mathrm{O}$ bonding at $286.8 \pm 0.1 \mathrm{eV}$, and $\mathrm{C}=\mathrm{O}$ bonding at $288.9 \pm 0.1 \mathrm{eV}$ [34].

(a)

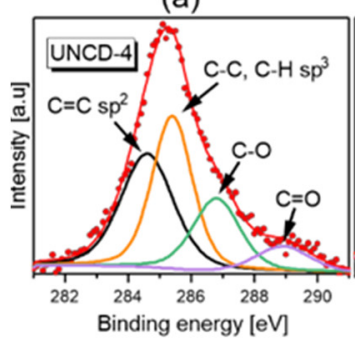

(b)

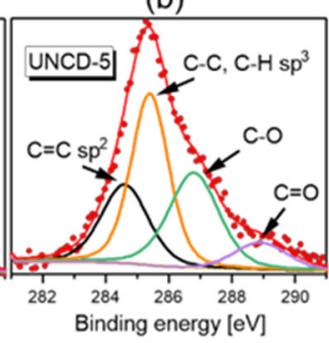

(c)

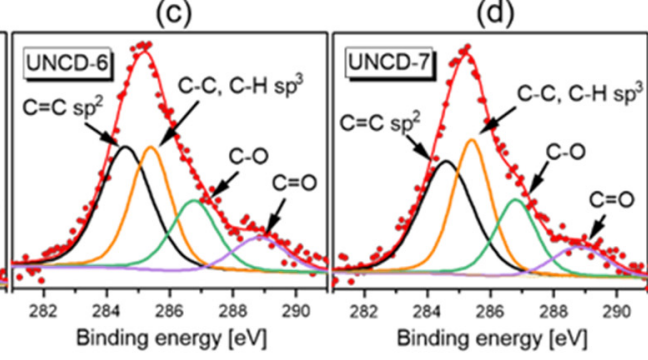

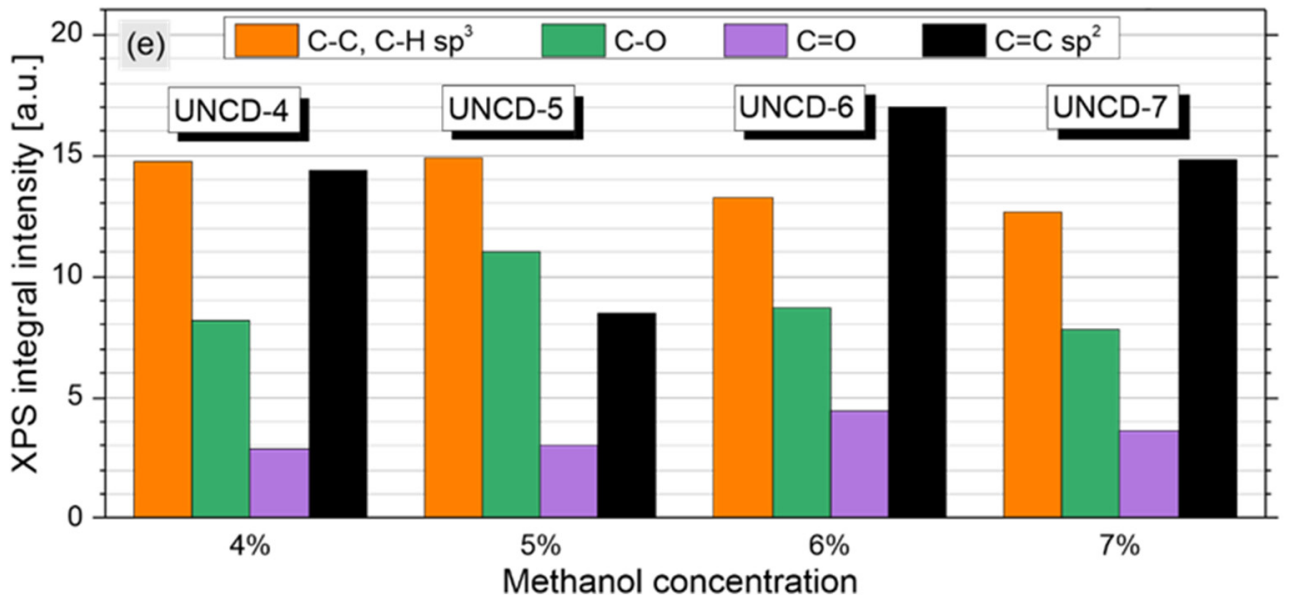

Figure 6. (a-d) XPS spectra of C 1s peak of UNCD films grown at different methanol concentrations. (e) Comparison of the results of $\mathrm{C} 1 \mathrm{~s}$ peak deconvolution with quantification of different carbon bonding states.

The XPS data confirmed the conclusions from the analysis of the first-order Raman spectra. Namely, we observed a slight decrease in the intensity of the $\mathrm{C} 1 \mathrm{~s}$ peak component attributed to the $\mathrm{C}-\mathrm{C}$ and $\mathrm{C}-\mathrm{H}$ bonding of carbon in tetrahedral configuration. Changes in the $\mathrm{C}=\mathrm{C} \mathrm{sp}^{2}$ peak intensity correlated with the G-band intensity in the Raman spectra. On the other hand, no regularity was found in the intensities of the $\mathrm{C}-\mathrm{O}$ and $\mathrm{C}=\mathrm{O}$ component of the $C 1$ s peak, which may be due to XPS being a surface technique.

\section{Conclusions}

In conclusion, the presented results show that UNCD properties can be modified by changing the methanol concentration in working gas during the CVD growth process. A slight change in the methanol concentration from 4 to $7 \%$ resulted in a reduction in the UNCD grains. At the same time, the resistivity of the films significantly increased, by more than one order of magnitude, which was attributed to the increase in the surface area of the diamond grains. The layers will ultimately be used as a transducer using an electrolyte (as an active layer in the sensor to determine the condition of drinking water), and thus, the minimum amount of admixtures is recommended. The admixtures additionally broke the crystal structure. By changing the methanol content, we changed the properties of the layer, which was our goal. 
Broad peaks at around $1310 \mathrm{~cm}^{-1}, 1420 \mathrm{~cm}^{-1}, 1525 \mathrm{~cm}^{-1}$, and $1590 \mathrm{~cm}^{-1}$ that were marked as $D_{1}, D_{2}, D_{4}$ and $G$ were visible in the Raman spectra. The XPS results showed four types of bonds of the diamond layers: $\mathrm{C}=\mathrm{C} \mathrm{sp}^{2}$ bonding at $284.5 \pm 0.1 \mathrm{eV}, \mathrm{C}-\mathrm{C}$ and $\mathrm{C}-\mathrm{H} \mathrm{sp}{ }^{3}$ bonding at $285.4 \pm 0.1 \mathrm{eV}, \mathrm{C}-\mathrm{O}$ bonding at $286.8 \pm 0.1 \mathrm{eV}$, and $\mathrm{C}=\mathrm{O}$ bonding at $288.9 \pm 0.1 \mathrm{eV}$. There was a visible relationship between the results of the Raman and XPS spectroscopy. Changes in the $\mathrm{C}=\mathrm{C} \mathrm{sp}^{2}$ peak intensity correlated with the G-band intensity in the Raman spectra.

The Raman and XPS results showed changes in the structure of UCNDs. Namely, the increasing of the concentration of methanol resulted in a slight decreasing of the $\mathrm{sp}^{3}$ phase content. At the same time, the concentration of the $-\mathrm{H},-\mathrm{OH}$, and $=\mathrm{O}$ groups increased with the increasing of the methanol concentration.

The presented results confirm that doping is not needed to change the properties of diamond layers. The appropriate selection of process parameters can lead to the modification of the $\mathrm{sp}^{3} / \mathrm{sp}^{2}$ proportion, which makes it possible to obtain layers with the required properties, and this, has very wide applicability.

Author Contributions: L.M.: Conceptualisation, Formal analysis, Investigation, Writing-review and editing, Data curation; R.S.: Raman Spectroscopy measurements, SEM, Writing-review and editing, M.T.: XPS measurements, Writing—review and editing; M.K.N.: AFM measurements, Writing—review and editing. All authors have read and agreed to the published version of the manuscript.

Funding: Polish National Science Centre (NCN); MINIATURA 3 numbered as 2019/03/X/ST8/01822.

Institutional Review Board Statement: Not applicable.

Informed Consent Statement: Not applicable.

Data Availability Statement: Not applicable.

Acknowledgments: This work was supported by Bydgoszcz Water Supply and Sewerage System.

Conflicts of Interest: The authors declare that they have no known competing financial interests or personal relationships that could have appeared to influence the work reported in this paper.

\section{References}

1. Bala, W.; Zorenko, Y.; Savchyn, V.; Voznyak, T.; Paprocki, K.; Popielarski, P.; Szybowicz, M. Optical and electrical properties of zno thin films grown by sol-gel method. In Solid State Phenomena; Trans Tech Publications Ltd.: Freienbach, Switzerland, 2013; pp. 14-21.

2. Popielarski, P.; Mosinska, L.; Bala, W.; Paprocki, K.; Zorenko, Y.; Zorenko, T.; Sypniewska, M. Persistent photoconductivity in $\mathrm{ZnO}$ thin films grown on Si substrate by spin coating method. Opt. Mater. 2019, 97, 109343. [CrossRef]

3. Popielarski, P.; Bala, W.; Paprocki, K.; Mosinska, K.; Kowalska, M.; Szybowicz, M.; Makowiecki, J. Admittance spectroscopy of CuPC-Si and CoPC-Si heterostructures. Electrochim. Acta 2013, 104, 496-504. [CrossRef]

4. Sun, J.; Ge, J.; Liu, W.; Lan, M.; Zhang, H.; Wang, P.; Wang, Y.; Niu, Z. Multi-enzyme co-embedded organic-inorganic hybrid nanoflowers: Synthesis and application as a colorimetric sensor. Nanoscale 2014, 6, 255-262. [CrossRef]

5. Riedinger, A.; Pernia Leal, M.; Deka, S.R.; George, C.; Franchini, I.R.; Falqui, A.; Cingolani, R.; Pellegrino, T. "Nanohybrids" based on pH-responsive hydrogels and inorganic nanoparticles for drug delivery and sensor applications. Nano Lett. 2011, 11, 3136-3141. [CrossRef] [PubMed]

6. Lee, B.R.; Choi, H.; SunPark, J.; Lee, H.J.; Kim, S.O.; Kim, J.Y.; Song, M.H. Surface modification of metal oxide using ionic liquid molecules in hybrid organic-inorganic optoelectronic devices. J. Mater. Chem. 2011, 21, 2051-2053. [CrossRef]

7. Švorc, L'; Stanković, D.M.; Kalcher, K. Boron-doped diamond electrochemical sensor for sensitive determination of nicotine in tobacco products and anti-smoking pharmaceuticals. Diam. Relat. Mater. 2014, 42, 1-7. [CrossRef]

8. Wang, P.; Yuan, X.; Cui, Z.; Xu, C.; Sun, Z.; Li, J.; Liu, J.; Tian, Y.; Li, H. A Nanometer-Sized Graphite/Boron-Doped Diamond Electrochemical Sensor for Sensitive Detection of Acetaminophen. ACS Omega 2021, 6, 6326-6334. [CrossRef]

9. Michnik, A.; Kłos, A.; Drzazga, Z. The influence of radio-frequency radiation on thermal stability of bovine serum albumin in aqueous solution. J. Therm. Anal. Calorim. 2004, 77, 269-277. [CrossRef]

10. Klos-Witkowska, A. Influence of fractional electromagnetic radiation doses on biosensor matrix component stability. Acta Phys. Pol. A 2018, 133, 101-104. [CrossRef]

11. Mosińska, L.; Popielarski, P.; Fabisiak, K.; Dychalska, A. Effects of hydrogen termination of CVD diamond layers. Opt. Mater. 2020, 101, 109676. [CrossRef] 
12. Ferrari, A.C.; Robertson, J. Raman spectroscopy of amorphous, nanostructured, diamond-like carbon, and nanodiamond. Philos . Trans. R. Soc. Lond. Ser. A Math. Phys. Eng. Sci. 2004, 362, 2477-2512. [CrossRef]

13. Chen, Y.-C.; Lee, D.-C.; Tsai, T.-Y.; Hsiao, C.-Y.; Liu, J.-W.; Kao, C.-Y.; Lin, H.-K.; Chen, H.-C.; Palathinkal, T.J.; Pong, W.-F.; et al Induction and regulation of differentiation in neural stem cells on ultra-nanocrystalline diamond films. Biomaterials 2010, 31, 5575-5587. [CrossRef]

14. Chen, X.; Mohr, M.; Brühne, K.; Fecht, H.-J. Highly Conductive Nanocrystalline Diamond Films and Electronic Metallization Scheme. Materials 2021, 14, 4484. [CrossRef]

15. Zhou, A.; Pacheco, E.; Zhou, B.; Feng, P. Size-Dependent Electrical Transport Properties in Conducting Diamond Nanostripes. Nanomaterials 2021, 11, 1765. [CrossRef]

16. Yao, Y.; Sang, D.; Duan, S.; Wang, Q.; Liu, C. Review on the Properties of Boron-Doped Diamond and One-Dimensional-MetalOxide Based PN Heterojunction. Molecules 2021, 26, 71. [CrossRef] [PubMed]

17. Sun, L.; Zuo, X.; Guo, P.; Li, X.; Ke, P.; Wang, A. Role of deposition temperature on the mechanical and tribological properties of $\mathrm{Cu}$ and $\mathrm{Cr}$ co-doped diamond-like carbon films. Thin Solid Films 2019, 678, 16-25. [CrossRef]

18. Bogdanowicz, R.; Sobaszek, M.; Sawczak, M.; Grigorian, G.; Ficek, M.; Caban, P.; Herman, A.; Cenian, A. Enhanced boron doping of thin diamond films grown in deuterium-rich microwave plasma. Diam. Relat. Mater. 2019, 96, 198-206. [CrossRef]

19. Robertson, J. Diamond-like amorphous carbon. Mater. Sci. Eng. R Rep. 2002, 37, 129-281. [CrossRef]

20. Booth, L.; Catledge, S.A.; Nolen, D.; Thompson, R.G.; Vohra, Y.K. Synthesis and characterization of multilayered diamond coatings for biomedical implants. Materials 2011, 4, 857-868. [CrossRef]

21. Puttichaem, C.; Souza, G.; Ruthe, K.; Chainok, K. Characterization of Ultra-Thin Diamond-Like Carbon Films by SEM/EDX. Coatings 2021, 11, 729. [CrossRef]

22. Surovtsev, N.V.; Kupriyanov, I.N. Effect of nitrogen impurities on the Raman line width in diamond, revisited. Crystals 2017, 7, 239. [CrossRef]

23. Granger, M.; Xu, J.; Strojek, J.W.; Swain, G. Polycrystalline diamond electrodes: Basic properties and applications as amperometric detectors in flow injection analysis and liquid chromatography. Anal. Chim. Acta 1999, 397, 145-161. [CrossRef]

24. Ramos, S.C.; Azevedo, A.F.; Baldan, M.R.; Ferreira, N.G. Effect of methane addition on ultrananocrystalline diamond formation: Morphology changes and induced stress. J. Vac. Sci. Technol. A Vac. Surf. Films 2010, 28, 27-32. [CrossRef]

25. Shroder, R.E.; Nemanich, R.J.; Glass, J.T. Analysis of the composite structures in diamond thin films by Raman spectroscopy. Phys. Rev. B 1990, 41, 3738. [CrossRef]

26. Prawer, S.; Nugent, K.; Jamieson, D.; Orwa, J.; Bursill, L.; Peng, J. The Raman spectrum of nanocrystalline diamond. Chem. Phys. Lett. 2000, 332, 93-97. [CrossRef]

27. Prawer, S.; Nemanich, R.J. Raman spectroscopy of diamond and doped diamond. Philos. Trans. R. Soc. Lond. Ser. A Math. Phys. Eng. Sci. 2004, 362, 2537-2565. [CrossRef] [PubMed]

28. Wang, C.Z.; Ho, K.M. Structure, dynamics, and electronic properties of diamondlike amorphous carbon. Phys. Rev. Lett. 1993, 71, 1184. [CrossRef] [PubMed]

29. Lin-Chung, P. Local vibrational modes of impurities in diamond. Phys. Rev. B 1994, 50, 16905. [CrossRef]

30. Bosak, A.; Krisch, M. Phonon density of states probed by inelastic X-ray scattering. Phys. Rev. B 2005, 72, 224305. [CrossRef]

31. Klauser, F.; Steinmüller-Nethl, D.; Kaindl, R.; Bertel, E.; Memmel, N. Raman studies of nano-and ultra-nanocrystalline diamond films grown by hot-filament CVD. Chem. Vap. Depos. 2010, 16, 127-135. [CrossRef]

32. Dychalska, A.; Koczorowski, W.; Trzcinski, M.; Mosińska, L.; Szybowicz, M. The Effect of Surface Treatment on Structural Properties of CVD Diamond Layers with Different Grain Sizes Studied by Raman Spectroscopy. Materials 2021, $14,1301$. [CrossRef] [PubMed]

33. Vecera, P.; Chacón-Torres, J.C.; Pichler, T.; Reich, S.; Soni, H.R.; Görling, A.; Edelthalhammer, K.; Peterlik, H.; Hauke, F.; Hirsch, A. The First Precise Determination of Graphene Functionalisation by in situ Raman Spectroscopy. arXiv 2017, arXiv:1703.02498.

34. Chu, P.K.; Li, L. Characterization of amorphous and nanocrystalline carbon films. Mater. Chem. Phys. 2006, 96, 253-277. [CrossRef] 